\title{
Post-Operative Wound Infections in Belize
}

\author{
Maj J C Allen *
}

FRCS (Glas), RAMC

Senior Specialist in Surgery

BMH Berlin, BFPO 45

\author{
Maj I D Crate \\ FRCS(Ed), RAMC \\ Senior Specialist in Surgery \\ Cambridge Military Hospital, Aldershot, Hants GU11 $2 A N$
}

\author{
Maj N B Corner \\ FRCS, RAMC \\ Senior Specialist in Surgery \\ Queen Elizabeth Military Hospital, Woolwich, London SE18 4QH
}

SUMMARY: The incidence of post-operative wound infections in Belize in 1986 and 1987 was studied. Both militar practice in the military hospital and civilian practice in the rural hospitals of the local towns were included. Despite previous misgivings and sub-optimal conditions in the rural hospitals an acceptably low incidence was found in both areas of work.

\section{Introduction}

Post-operative wound infection remains a challenge to surgeons, causing significant mortality and morbidity even in the modern hospitals of the West. Much research has been carried out, with over 6,000 articles on the subject published in the 10 years 1977-87. However, little work has been published on wound infection in the rural hospitals of the Third World.

Belize (formerly British Honduras) is a small Commonwealth nation on the Eastern seaboard of Central America with a population of about 150,000 . There is a small garrison of British troops medically supported by a Field Surgical Team (FST) based at the Military Hospital at Airport Camp.

The FST provides surgical cover for the British troops and also supplies a surgical facility for the local Belizeans at centres of population other than the largest town, Belize City (where the two local surgeons are based). The voluntary civilian work consisted of weekly visits to the rural hospital at Orange Walk, in the sugar growing north of the country, and to the hospital at Belmopan, the administrative capital inland. There were also less regular visits to the rural hospital at the port of Punta Gorda in the south and to the medical mission in the village of Crique Sarco, also in the south.

Emergencies arising amongst British troops were dealt with at Airport Camp and, if necessary, surgery was carried out in the modern operating theatre there. Elective cases were also seen at Airport Camp and either received appropriate surgery, air evacuation to the UK or treatment was deferred until the patient's planned *Now Cambridge Military Hospital, Aldershot, Hants GU11 2 AN

return to the UK. The accepted surgical brief for Befize states that post-operative wound infections are nore common than in the UK, but that the local popula\&ont appears to be exempt. We wished to examine the cidence of post-operative wound infection in Belizêे both servicemen and local civilians for the years 19867

\section{Method}

This study consisted of a review of cases for 1986 and $\vec{g}$ prospective study throughout 1987.

The operating theatre at Airport Camp (APC) is purpose-built modern suite which is regularly fumigated and checked with settle plates to ensure an acceptab low level of airborne contamination. The theatre is ai conditioned with a separate transfer area to reduc contamination. There is also an autoclave where all sets and linen for both APC and civilian practice are sterilised.

At Orange Walk the operating theatre is a room at the end of an external corridor (Fig 1) with two holes in the wall where the air-conditioners used to be. There is a operating table but no change of clothing for operating. There is a similar arrangement at Punta Gorda whilst al Crique Sarco patients were operated on in an upstaip bedroom converted for the occasion using the kitchen table. At Belmopan there is a purpose built operatires suite with air conditioning (Fig 2). Theatre blues, sterites gown etc are worn for surgery.

In the prospective study settle plates were used APC, Orange Walk and Belmopan to assess the level of 


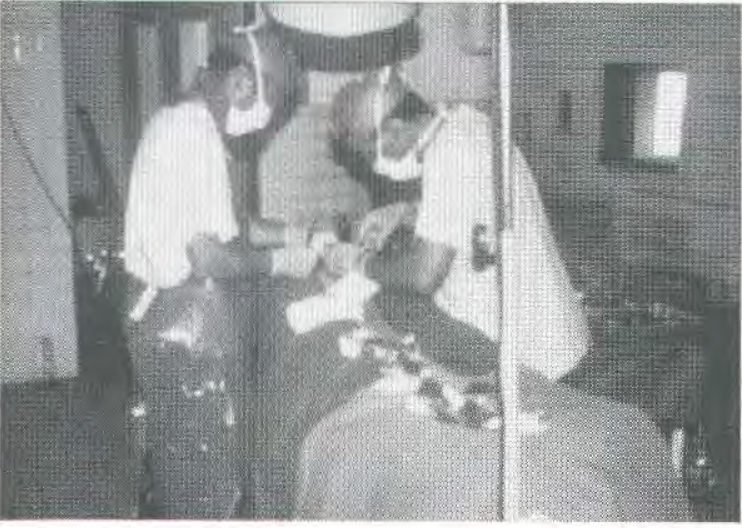

Fig 1. The operating theatre at Orange Walk.

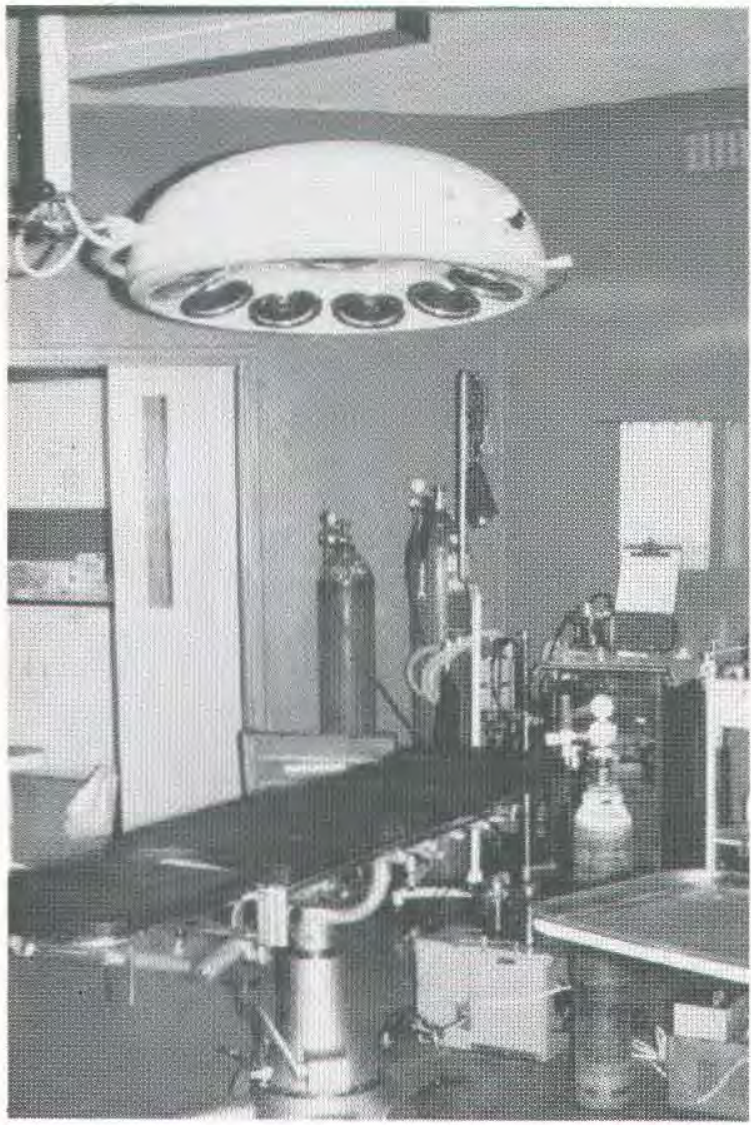

Fig 2. The operating theatre at Belmopan.

airborne bacteria. They were opened for one hour prior to using the theatre. In the review a case was deemed infected if it so stated in the post-operative and followup notes. In the prospective study a case was considered infected if, at review, pus or wound breakdown was found.
Operations were divided into two groups: (Figs 3 \& 4)

\begin{tabular}{lcc} 
& APC & Civilian Practice \\
\hline Skin Ops & 14 & 9 \\
Tubal ligation & - & 43 \\
Hernia & 3 & 25 \\
Laceration & 9 & - \\
IGTN & 8 & - \\
Appendix & 7 & - \\
Circumcision & 7 & - \\
Orthopaedic & 10 & 7 \\
Cholecystectomy & - & 4 \\
Miscellaneous & 19 & 18 \\
\hline
\end{tabular}

Fig 3. The breakdown of operations for 1986 .

\begin{tabular}{lcc} 
Operations & APC & Civilian Practice \\
\hline Tubal ligation & - & 33 \\
Hernias & 2 & 48 \\
Ex biopsy & 36 & 24 \\
Cholecystectomy & - & 7 \\
Appendix & 4 & - \\
Orthop & - & 9 \\
Others & 33 & 74 \\
\hline
\end{tabular}

Fig 4. The breakdown of operations for 1987.

1. Clean operations where no viscus was opened and $\bar{\sigma}$ there was no other source of wound contamination. $\Omega$ ! 2 . Contaminated and potentially contaminated procedures where there was either a known source of infection or contamination such as an opened viscus.

The range of operations carried out varied with the locality. At Airport Camp the largest group was excision of skin lesions such as naevae and epidermoid cysts with a smaller number of hernias, circumcisions and such emergencies as lacerations and appendicectomies. In the civilian work there was a strong gynaecological bias, the commonest operation in 1986 being tubal ligation. There were also many herniorrhaphies and other miscellaneous procedures.

\section{Retrospective Study 1986}

At Airport Camp the case notes for 1986, excluding those sent to the UK with evacuated patients and those misplaced, were examined for evidence of post-operative wound infection. At Orange Walk and Belmopan the available notes for 1986 were reviewed for reference to wound infection. In Orange Walk the outpatients register was also reviewed as the nurse in Outpatients routinely commented on the presence of infection.

At Crique Sarco the notes were reviewed, but at Punta Gorda the medical records were extremely disorganised and due to the restrictions in time no review was undertaken. 


\section{Prospective study of 1987}

At Airport Camp all patients were reviewed daily postoperatively and any infection recorded. In the civilian work as many patients as possible were reviewed one week post-operatively at the next visit, and the wound checked for infection.

Rates of infection were calculated for each three monthly surgeons tour, and for each year. The annual rate of infection was compared to that obtained by one surgical firm at the Cambridge Military Hospital, Aldershot.

Pairwise comparisons of rates of infection between the 3 groups (i.e. Airport Camp, Belizean Civilian and the $\mathrm{CMH}$ ) for 1986 and 1987 and for clean and contaminated cases were made using the chi-squared test incorporating Yates continuity correction for $2 \times 2$ contingency tables of frequencies.

\section{Results}

\section{Settle plate counts}

At Airport Camp these are very low, on a par with those found in the UK. The counts at Orange Walk and Belmopan were extremely high with a wide range of organisms found (Fig 5).

\begin{tabular}{cccc} 
& Airport Camp & Belmopan & $\begin{array}{c}\text { Orange } \\
\text { Walk }\end{array}$ \\
\hline Plate & & & \\
1 & 1 & 25 & 110 \\
2 & 0 & 9 & 120 \\
3 & 0 & 350 & 170 \\
4 & 1 & 100 & 100 \\
5 & 2 & 200 & 160 \\
6 & 1 & 150 & 180 \\
7 & 1 & 250 & 80 \\
8 & 1 & 40 & 170 \\
\hline
\end{tabular}

Fig 5. Settle plate counts, 1987.

\section{Review of 1986 (Figs 6\& 7)}

At Airport Camp there was an overall wound infection rate in clean cases of nearly $10 \%$, with 6 infections in 62 cases. However 5 of these occurred with one surgeon, the other 3 surgeons mustering only one infection

\begin{tabular}{lccc} 
& Cases & Infected & $\%$ \\
\hline Clean & 625 & 16 & 2.6 \\
Contaminated & 123 & 10 & 8.1 \\
\hline
\end{tabular}

Fig 7. The number and incidence of post-operative wound infections in Clean and Contaminated cases for one surgical firm at the Cambridge Military Hospital, Aldershot for 1986.

between them with their combined rate being only $2 \%$. In the civilian role there was no excess of infections by any one surgeon and the overall infection rate was only on $1.9 \%$. The total wound infection rate at APC is significantly greater than at civilian hospitals $(p 0.01)$ or in the UK (p 0.05). The figures for civilian practice are not statistically significantly different from the UK. There were only 23 contaminated cases overall with 4 infections, but the numbers were too few to permit valid statistical analysis.

\section{Prospective study 1987 (Fig 8)}

There were significantly more cases included in the analysis. The total infection rates for clean cases was about 3\% and for contaminated cases between 10 an $18 \%$. No one surgeon had an excess of wound infection and there were no statistically significant differences found between any group and the UK figures.

\section{Discussion}

Post-operative wound infection is a subject of intense research, but of the nearly 6,000 papers published on that theme in the 10 years 1977 to 1987 only 37 originated in the tropics with only 27 coming from developing countries. Only two publications included work done in rural hospitals.

Amongst the papers published from the Western world are several large series of between 15,000 and 62,000 patients $(1,2,3)$. Several classification systems of wound infection have been used, but if pus formation or wound breakdown is taken as the definition of infection then the incidence of infection in clean wounds in most series is less than $3 \%$ - similar to that found in the $\mathrm{CMH}$ and in Belize. This definition was used in this study as an easily recognisable end-point reduces observer variation

\begin{tabular}{lccccccccc} 
& \multicolumn{3}{c}{ Airport Camp } & \multicolumn{3}{c}{ Civilian Practice } & \multicolumn{3}{c}{ Total } \\
& Cases & Infected & $\%$ & Cases & Infected & $\%$ & Cases & Infected & $\%$ \\
\hline Total 4 Surgeons & 62 & 6 & 9.8 & 106 & 2 & 1.9 & 165 & 8 & 4.8 \\
Total 3 Surgeons & 47 & 1 & 2.1 & 82 & 1 & 1.2 & 129 & 2 & 1.5 \\
\hline
\end{tabular}

Fig 6. The number and incidence of post-operative wound infections in both Clean and Contaminated cases at APC and in Civilian Practice for 1986. 


\begin{tabular}{lccccccccc} 
& \multicolumn{3}{c}{ Airport Camp } & \multicolumn{3}{c}{ Civilian Practice } & \multicolumn{3}{c}{ Total } \\
& Cases & Infected & $\%$ & Cases & Infected & $\%$ & Cases & Infected & $\%$ \\
\hline Clean & 71 & 2 & 2.8 & 197 & 6 & 3.0 & 268 & 8 & 2.9 \\
Contaminated & 16 & 3 & 18.7 & 30 & 3 & 10.0 & 46 & 6 & 13.0 \\
\hline
\end{tabular}

Fig 8. The number and incidence of post-operative wound infections in both Clean and Contaminated cases at APC and in Civilian Practice for 1987.

(2) and enables accurate figures to be obtained from a sequence of surgeons.

\section{Settle plate counts}

These demonstrate the effectiveness of the regimen at APC in reducing the number of airborne organisms to a very low level compared to the large number and variety of species found at Orange Walk and Belmopan. This difference is not reflected in any difference in the incidence of post-operative wound infection.

\section{Airport Camp}

At the APC the operating conditions were similar to those found in the Western world and in the teaching hospitals of the developing world. The follow up is thorough and complete, and would have identified all post-operative infections.

The work load in Belize is not strictly comparable to that in the UK, as very few operations in APC take more than half an hour, as compared to the UK where there are proportionally more longer procedures. It is known that the infection rate approximately doubles for each hour of surgery $(2,4)$. A work load of shorter cases should help towards the acceptably low incidence of post-operative wound infection. However, such infections as did occur did not do so in the few long cases undertaken. There is certainly no greater risk of wound infection as predicted in the brief. The study covered 2 complete years and 7 different surgeons. There is no detectable difference in wound infection due to the differing humidity of the wet and dry seasons.

Surgeon variability - even in the Third World - is a known factor in post-operative wound infection (6). The surgeons involved in the study all held the Fellowship of one of the surgical Royal Colleges, but their seniority and experience was varied. The surgeon with an excess of wound infections was relatively junior. The fears of wound infection expressed in the standard surgical brief do not seem to be justified.

\section{Belizean Civilian Practice}

As far as we are aware, this is the only report in the English language on post-operative wound infections in rural hospitals in a developing country. There is a French language report from Burkino-Faso (7) on 81 patients with a post-operative infection rate of $14 \%$. A report from East Germany (8) on a much larger series of 274 patients in a tented hospital in Managua, Nicaragua, where the surgery was carried out in an air conditioned purpose-built container which was regularly cleaned with antiseptics, was more comparable with the work load in Belize. The post-operative wound infection rate in this series was $2.6 \%$.

The operating conditions at Orange Walk, Belmopan, Punta Gorda and Crique Sarco are nothing like those found at APC or Western-style hospitals, especially as regards conditions of cleanliness and ventilation taken for granted in the West. There is, however, no increase in post-operative infections. This has been noted before in a rural hospital in Central Africa (J.A. unpublished observations). The follow up in Belizean civilian practice was over $90 \%$ at one week in the prospective study and should have enabled the majority of infections to be detected.

The influence of airborne contamination in wound infection is open to debate $(5,14,15,17)$. In the operating conditions of New York in 1901 the incidence of postoperative wound infection in clean cases was only $3.2 \%$ (9), and other studies have found that the pathogenic organisms in post-operative wound infections are those found in ward air or shed from medical and nursing staff (10). Beagston (11) showed no correlation between Staph. aureus in the air and post-operative Staph. aureuse infections, and Drake (12) found no difference in the? incidence of wound infection between cases operated on in a theatre with or without air filtration. Most wound infections are endogenous rather than exogenous and the results from Belize would seem to confirm the relatively minor importance of airborne contamination in general surgery.

Other factors (age, nutrition, length of operation etc) $(2,13,15,16)$ are also known to affect the risk of wound infection. The older the patient the greater the risk of infection, but the demography of Belize ensures the majority of the patients are under 60 years old (i.e. young). The patients seen are farm labourers and the like, and their nutritional state is unlikely to be so bad as to constitute a risk. The patients are also only admitted on the day of operation, reducing the known risk of preoperative stay, and any shave is done immediately preoperatively.

The work load in Belize, both at APC and in civilian practice, has few lengthy procedures, and is not strictly comparable to other published series from developed countries. Shorter procedures such as herniorrhaphies provide the commonest clean operations in most series, and there is no excess of infections in the longer cases done. Surgical expertise, related to experience, reduces 
the risk of infection by careful dissection and avoiding both haematomata and excessive devitalised tissue in ligatures or damaged by diathermy. Surgeons in Belize range from registrar to consultant but all have a surgical Fellowship. Adequate expertise contributes to the low incidence of infection.

The fears generally expressed concerning post-operative wound infections in British personnel subjected to surgery in Belize would not appear to be justified, and the impressively low incidence of post-operative infection in the civilian population operated on in rural hospitals is confirmed. Contributing factors must include relative youth, short procedures and efficient sterilisation of instruments and linen, combined with effective surgical technique.

\section{Acknowledgement}

We wish to thank Mrs Margaret Sims, MEDSTATS Stanmore for statistical help.

\section{REFERENCES}

1. Hulton N R, Kiff E S, Brogan T D. Surgical sepsis at a district general hospital. J Hosp Inf 1985; 6: 140-146.

2. CRUSE P J E, Foord R. The Epidemiology of Wound Infection: a 10 year prospective study of 62,939 wounds. Surg Clin North Am 1980; 60: 2740.

3. LEIGH D A. An eight year study of postoperative wound infection in two district general hospitals. $J$ Hosp Inf 1981; 207-217.

4. Prabhaker P, Raje D, Castle D. et al. Nosocomial surgical infections: incidence and cost in a developing country. Am JInf Control 1983; 11: 51-86.

5. Shaw D, Doig C M, Douglas D. Is airborne infection in operating theatres an important cause of wound infection in general surgery? Lancet 1973; i: 17-20.
6. RABA'A S M A E, IBRAHIM A. Early postoperative wound infection in clean surgery at Khartoum. East Afr Med J 1987; 64: 183-189.

7. Mianne D, Dehaye B, Compaore A, Guinard D. L'exposition precoce a l'air libre des plaies operatoires abdominales. Med Trop 1986; 46: 371음 374.

8. RUPPRECht VON H, WaCKS J H, Schuhr E U $\vec{\Rightarrow}$ SCHALLER H. Zur Wundheiling nach geplanten? aseptischen Operationen unter den Bedingunger? eines Zelthospitals in den Tropen. Zentral bl Chi 1987; 112: 1561-1565.

9. LUKE W P. Surgical infections - the general sur $\mathbb{\Omega}$ geons perspective. Postgrad Med 1986; 80: 74-84.

10. Jepson O B, Larson S O, Thomsen V F. Post-oper ative wound sepsis in general surgery. Acta Chi $\overrightarrow{0}$ Scand (Suppl) 1969; 396: 73-79.

11. Bengtsson S, Hambraeus A, Laurell G. Woundo infections after surgery in a modern operating suite? clinical, bacteriological and epidemiological finds J Hyg Camb 1979; 83: 41-47.

12. Drake C T, Goldman E, Nicholls $R$ L PiatruszKa K, Nyhus L M. Environmental air and airborne infections. Ann Surg 1977; 185: 219-223.

13. Altemeier W A, Culbertson W R, Hummel R P Surgical considerations of endogenous infections -8 sources, types and methods of control. Surg Ctior North Am 1968; 48: 227-240.

14. Kundsin R B. Documentation of airborne infect during surgery. Ann N Y Acad Sci 1980; 353: 2क़ 261.

15. Cruse P J E. Wound infection surveillance. Infect Dis 1981; 3: 734-737.

16. Christou N V, Nohr C W, Meakins J L. Assessi operative site infection in surgical patients. $A$ ge Surg 1987;122: 165-169.

17. Davidson A I G, Smith $G$, Smylie H G. F bacteriological study of the immediate environmen of a surgical wound. Br J Surg 1971; 58: 326-333. 